\title{
ANALISIS DAYA TARIK PADA IKLAN NEGO CINCAI DI BUKALAPAK
}

\author{
Ricky Amar Satria ${ }^{1)}$, Rahmat Ihsanul Fajar'2), Puji Anto ${ }^{3)}$ \\ Program Studi Desain Komunikasi Visual, \\ Fakultas Bahasa dan Seni, Universitas Indraprasta PGRI \\ Jl. Nangka No. 58 C, Tanjung Barat, Jakarta 12530, Indonesia \\ rickysatria30@gmail.com
}

\begin{abstract}
Abstrak
Tujuan pembuatan analisi ini adalah untuk memberitahu daya tarik apa saja yang digunakan pada iklan Bukalapak Nego Cincai ini. Karena iklan Bukalapak ini cukup menarik perhatian masyarakat Indonesia. Bukalapak merupakan e-commerce yang cukup populer dikenal masyarakat Indonesia. Selain karena kepercayaan masyarakat pada Bukalapak, hal tersebut disebabkan oleh rangkaian iklan yang disampaikan dalam bentuk video dengan gaya yang khas berupa paduan musikal dan humor dan juga visual yang ditampilkan. Penelitian ini menggunakan metode penelitian kualitatif dengan studi literatur. Dalam menganalisis iklan Bukalapak ini kami menggunakan beberapa pemikiran-pemikiran para ahli di bidang periklanan.
\end{abstract}

Kata Kunci: iklan, daya tarik, bukalapak, nego cincai

\begin{abstract}
The purpose of this analysis is to tell what appeal is used in this Bukalapak Nego Cincai ad. Because this Bukalapak advertisement attracts the attention of the Indonesian people. Bukalapak is e-commerce which is quite popular known by the people of Indonesia. Apart from the community's trust in Bukalapak, this was caused by a series of advertisements delivered in the form of videos with a distinctive style in the form of a mixture of musical and humor and also visuals displayed. This study uses qualitative research methods with literature studies. In analyzing this Bukalapak advertisement we used several ideas from experts in the field of advertising.
\end{abstract}

Keywords: advertising, attraction, bukalapak, nego cincai

Correspondence author: Ricky Amar Satria, rickysatria30@gmail.com, Jakarta, Indonesia

This work is licensed under a $C C-B Y-N C$

\section{PENDAHULUAN}

E-commerce bermula di awal tahun 1970-an, dengan adanya inovasi semacam electronic fund transfer (EFT). Pada masa itu penggunaan aplikasi masih terbatas pada lembaga keuangan, dan beberapa perusahaan kecil yang nekat lalu muncullah electronic data interchange (EDI), 
dan terus berkembang dari transaksi keuangan lalu beralih ke pemrosesan transaksi yang lain serta memperbesar jumlah perusahaan yang ikut serta serta, mulai dari lembaga keuangan hingga perusahaan-perusahaan manufaktur, ritel, layanan dan lainnya. Aplikasi-aplikasi lain kemudian ikut menyusul, yang memiliki jangkauan dari perdagangan saham hingga sistem reservasi perjalanan. Pada masa itu sistem tersebut disebut sebagai aplikasi telekomunikasi yang nilai strategisnya sudah dikenal secara umum. Dengan adanya komersialisasi internet pada awal tahun 1990-an, serta berkembang pesatnya pertumbuhan yang mencapai hingga jutaan pelanggan potensial, maka muncullah istilah electronic commerce (e-commerce), yang aplikasinya segera berkembang pesat (Suyanto, 2003b) dalam (Widagdo \& Mada, 2016).

Dengan berkembangnya e-commerce di Indonesia banyak produsen menggunakan sumber dayanya di dalam menciptakan suatu karya iklan yang dapat menarik perhatian pada konsumen sasarannya. Mengingat tingginya biaya yang harus dikeluarkan oleh perusahaan stasiun televisi bagi penayangan iklan, menuntut para tim kreatif periklanan untuk dapat menciptakan suatu karya iklan yang menarik, beda, dan unik dibandingkan iklan lainnya. Untuk dapat meraih perhatian dari khalayak, para praktisi iklan biasanya menggunakan beberapa pendekatan yang unik di dalam menonjolkan daya tarik pesan sebuah karya iklan yang mereka buat.

Persaingan dalam mengiklankan produk yang relatif sama menyebabkan usaha untuk merebut perhatian khalayak dalam iklan-iklannya semakin kompetitif. Oleh karena itu, perlu digunakan teknik-teknik periklanan yang kreatif dan menarik. Pada fenomena persaingan iklan yang terjadi tersebut, terlihat setiap pengiklan telah menggunakan unsur humor yang menjadi salah satu teknik persuasi dalam iklan. Humor disampaikan dengan cara yang berbeda sesuai dengan pesan yang ingin disampaikan. Masing-masing iklan operator memiliki strategi kreatif yang mempengaruhi pemilihan tipe humor yang digunakan mereka.

Menggunakan unsur humor dalam periklanan tujuannya adalah sebagai sarana untuk menciptakkan tujuan agar informasi yang disampaikan memicu perhatian, mengarahkan konsumen terhadap tuntutan produk, memengaruhi sikap, yang pada ahirnya menciptakan perilaku konsumen untuk membeli atau menggunakan produk.

Salah satu perusahaan yang menggunakan iklan di televisi untuk menawarkan promo adalah Bukalapak. Bukalapak merupakan salah satu toko online Indonesia yang menyediakan sarana jual-beli dari konsumen ke konsumen. Bukalapak memberikan jaminan 100\% uang kembali kepada pembeli jika barang tidak dikirimkan oleh pelapak (Zaky, 2014). Selain itu juga Bukalapak sering kali mengadakan promo pada jangka waktu tertentu. Pada tanggal 26-31 Januari 2017 yang berdekatan dengan Hari Raya Tahun Baru Cina/Imlek, Bukalapak memiliki promo Nego Cincai. Promo ini memberi kesempatan pada pembeli untuk menawar harga produk yang dijual di website tersebut, kecuali produk virtual misalnya pulsa handphone. Promo tersebut disampaikan kepada masyarakat melalui sebuah iklan. Iklan tersebut tersusun dari video dengan durasi 1 menit yang menampilkan figur wanita paruh baya dengan ciri-ciri ras Tionghoa yang sedang menyanyikan lagu yang liriknya mengenai promo Nego Cincai tersebut. Secara keseluruhan iklan ini memperlihatkan budaya khas Tionghoa. Hal ini terlihat dari penggunaan latar belakang, figur dan warna-warna yang dominan pada iklan tersebut. Secara verbal pun dominan menggunakan bahasa Tionghoa suku Hokkian. Upaya yang dilakukan oleh Bukalapak untuk menarik perhatian konsumen adalah mengangkat budaya Tionghoa. Dengan adanya keragaman budaya dan suku di Indonesia, hal ini menimbulkan pertanyaan mengapa Bukalapak memilih budaya Tionghoa dalam penyampaian iklannya dan bagaimana visualisasi budaya Tionghoa pada iklan Bukalapak Nego Cincai (Fahrini \& Franzia, 2017)

Daya tarik iklan mengacu pada pendekatan yang digunakan untuk menarik perhatian konsumen atau mempengaruhi perasaan konsumen terhadap suatu produk (barang atau jasa). Ada beberapa macam daya tarik yang biasa digunkan pada kegiatan periklanan yaitu daya tarik iklan rasional, daya tarik iklan emosional, dan daya tarik iklan campuran (Morissan, 2007)

Daya tarik rasional adalah daya taik yang lebih menekankan pada pemenuhan kebutuhan konsumen pada aspek praktis, fungsional, dan kegunaan produk dan jasa tersebut dan juga menekankan pada atribut yang dimiliki. Isi pesan dari iklan yang menggunkan daya tarik rasional lebih bersifat informatif, dan pemasangan iklan yang menggunakan daya tarik rasional memiliki 
tujuan untuk meyakinkan konsumen bahwa produk yang mereka pilih mempunyai manfaat yang dapat memenuhi dan memuaskan kebutuhan dari konsumen (Morissan, 2007)

Daya tarik emosional adalah daya tarik yang memiliki hubungan dengan kebutuhan sosial dan psikologi konsumen dalam pembelian suatu produk atau jasa. Tidak sedikit motif pembelian konsumen bersifat emosional karena perasaan mereka terhadap suatu merek dapat menjadi lebih penting daripada pengetahuan yang mereka miliki terhadap suatu merk. Dalam hal ini, Kebutuhan dan perasaan konsumen dapat dijadikan sebagi dasar dari daya tarik yang memiliki tujuan untuk mempengaruhi konsumen pada level emosional (Morissan, 2007). Daya tarik campuran atau mix adalah daya tarik yang menggabungkan dua daya tarik yang ada yaitu daya tarik rasional dan daya tarik emosional sehingga penggunaan daya tarik campuran ini sangatlah efektif jika digunakan pada iklan karena selain informasi atau pesan yang ingin disampaikan oleh produsen ke konsumen tersampaikan dan juga memberikan kebutuhan sosial dan psikologi konsumen dalam pembelian suatu produk.

\section{METODE PENELITIAN}

Metode penelitian merupakan langkah yang dimiliki dan dilakukan oleh peneliti dalam rangka mengumpulkan data serta melakukan investigasi pada data yang telah diperoleh. Metode ini bertujuan untuk menemukan pengetahuan baru secara ilmiah yang sebelumnya belum pernah diketahui. Pada penelitian ini, peneliti menggunakan metode penelitian kualitatif deskriptif. Penelitian dengan membuat deskripsi berdasarkan fakta-fakta yang berasal dari studi pustaka, observasi dan wawancara yang kemudian disusun secara sistematis dan akurat. Peneliti mengambil tinjauan pustaka utama dari buku berjudul periklanan komunikasi pemasaran terpadu yang merupakan sebuah buku pembelajaran periklanan. Buku tersebut di tulis oleh seorang ahli di bidang komunikasidan periklanan bernama Drs. Morissan, S.H, M.A.

\section{HASIL DAN PEMBAHASAN}

Analisis daya tarik pada iklan ini sebagai berikut, dalam video iklan Bukalapak Nego Cincai yang memiliki durasi 30 detik ini memperlihatkan latar belakang berupa bangunan dengan arsitektur khas etnis Tionghoa. Di bagian atas ada beberapa lampion khas etnis Tionghoa yang memiliki warna merah dan kuning. Pada bagian kiri dan kanan video terdapat sebuah pohon sakura yang memiliki warna daun merah muda. Pada bagian tengah terdapat sosok wanita berusia paruh baya atau sekitar 50 tahun dan wanita itu bernama bu Linda. Wanita tersebut terlihat mengenakan pakaian khas Tionghoa yang berwarna merah dengan kombinasi warna emas. Bagian depan rambutnya digulung ke atas menggunakan rol rambut berwarna merah muda. Selain itu ia terlihat sedang membawa sempoa, alat hitung tradisional dari Tiongkok (Fahrini \& Franzia, 2017)

Pada adegan pertama ini daya tarik yang digunakan adalah daya tarik emosional lebih tepatnya daya tarik humor karena adanya sosok wanita paru baya dengan dandanan yang menarik sehingga membuat para konsumen mudah mengingat iklan ini.

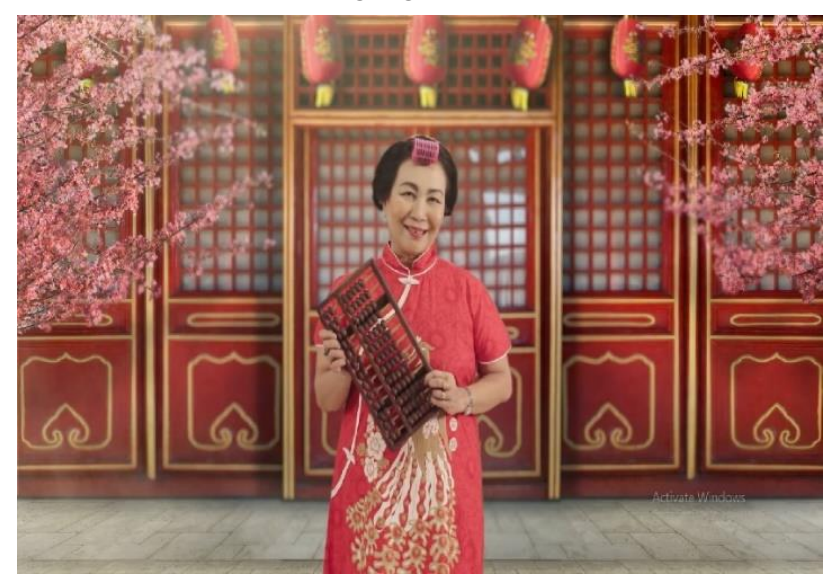

Gambar 1 Adegan petama iklan 
Setelah tokoh wanita tersebut muncul, nada alunan khas Tionghoa mulai terdengar disambung dengan tokoh wanita tersebut yang sedang bernyanyi.

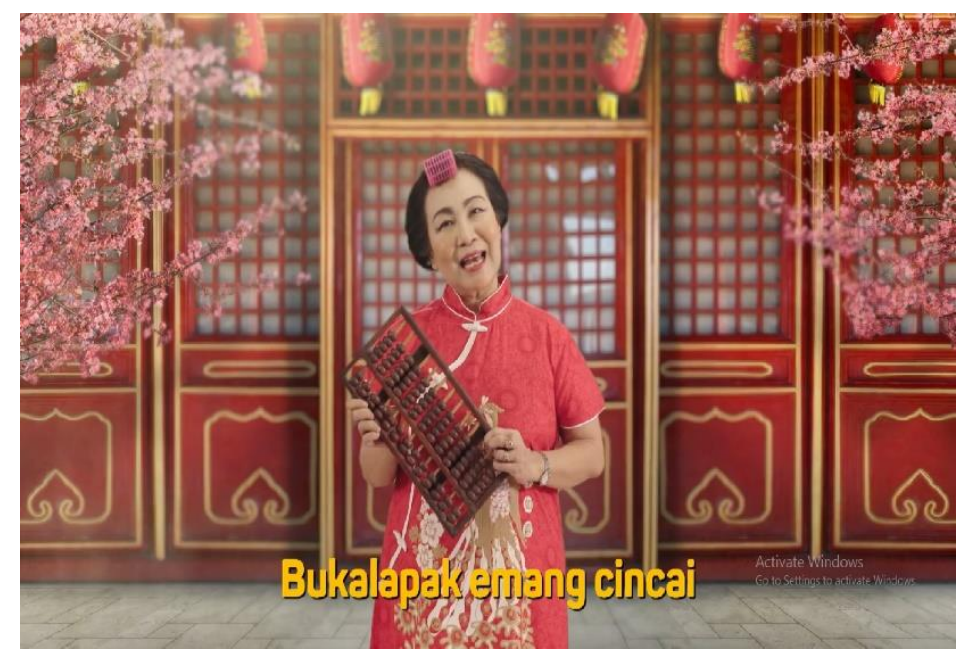

Gambar 2 Adegan wanita sedang bernyanyi

Berikut lirik lagu yang dinyanyikan oleh bu Linda adalah:

Bukalapak emang cincai.

Harga santai, kagak lebay.

Dinego aje say, pasti bisa say.

Dinego sampai hokcay.

Dinego aje say, pasti bisa say.

Dinego sampai hokcay.

Bahkan hanya dengan melihat sosok wanita tersebut yang cukup unik karena wanita ini bernyanyi sambil memegang sempoa dan terlebih lagi wanita ini masih menggunakan roll rambut yang berwarna pink itu, kita sudah tertarik melihat iklan tersebut. Dan ditambah dengan nyanyian dengan lirik yang tidak kalah unik juga. Dan pada pada saat wanita itu bernyanyi muncul teks dari lirik tersebut sehingga membuat iklan itu seperti video yang ada pada tempat karaoke dan hal itu membuat menjadi iklan ini lebih menarik dan membuat kita bisa mengetahui lirik dari iklan tersebut sehingga kita lebih mengingat lagu dari iklan ini. Meskipun lirik tersebut terbilang unik tetapi lirik tersebut tetap memiliki pesan yang ingin disampaikan kepada konsumennya, sehingga tidak menghilangkan fungsi dari iklan yaitu memberikan pesan kepada konsumenya. Hal itu lah yang membuat iklan ini menjadi iklan yang menarik sekaligus sukses dalam penyampaian pesannya.

Pada adegan kedua menggunakan daya tarik campuran, karena adanya informasi yang ingin disampaikan oleh produsen kepada konsumen tetapi dengan menggunkan beberapa kata yang lucu dan kata-kata yang berasal dari etnis Tionghoa seperti cincai dan hokcay. 


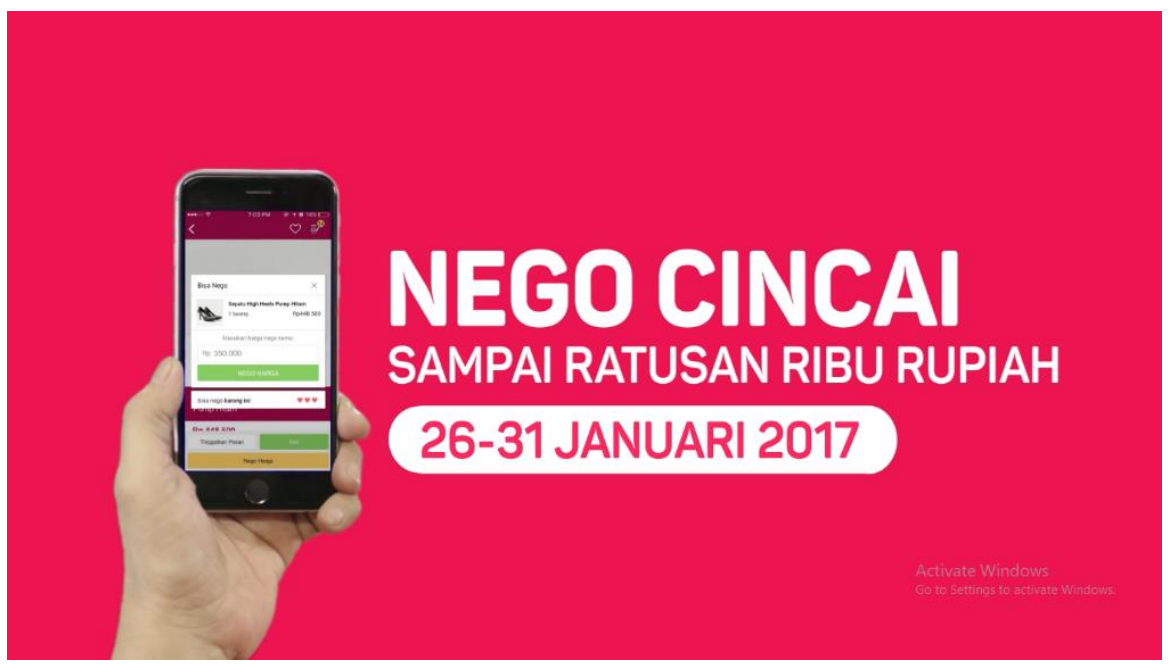

Gambar 3 Adegan terakhir

Setelah adegan bernyanyi ada adegan selanjutnya yaitu terdapat gambar tangan yang sedang memegang smartphone, dan ada sebuah tulisan "NEGO CINCAI SAMPAI RATUSAN RIBU RUPIAH 26-31 JANUARI 2017" dan saat adegan ini sedang berlangsung ada pembacaan narasi yang menggunakan suara wanita dengan nada gaya berbicara khas Tionghoa.Dan adegan ini lah yang menjadi penjelasan tambahan dari iklan Bukalapak nego cincai ini.

Pada adegan terakhir menggunakan daya tarik campuran karena pada adegan ini lebih menekankan pada aspek informasi hal ini memiliki daya tarik rasional tetapi adanya voice over suara wanita yang berbicara dengan gaya bicara khas Tionghoa sehingga juga memunculkan daya tarik emosional.

Pada Iklan Bukalapak Nego Cincai yang menggunakan konsep perayaan Imlek bukan hanya perayaan semata, melainkan sebagai momen untuk setiap orang agar dapat mempererat persaudaraan agar lebih menghargai keberagaman yang ada di Indonesia dengan cara saling menghargai dan menghormati satu sama lain. Imlek juga dapat menjadi pendorong pertumbuhan ekonomi. Alasannya, masyarakat di Indonesia khususnya etnis cenderung lebih banyak berbelanja ketika perayaan tersebut. Dan bersamaan dengan perayaan Imlek, Bukalapak menjadikan perayaan Imlek ini untuk meningkatkan niat berbelanja dan meningkatkan transaksi di tengah tren yang sedang lesu transaksi belanja pada masyarakat pasca perayaan tahun baru.(Triwijanarko, 2018)

Iklan Bukalapak Nego Cincai ini dapat dikatakan sukses karena mendapatkan berbagai apresiasi, dengan mendapatkan penghargaan Citra Pariwara 2017 dan Best Ads Youtube Pulse 2018. Sampai tanggal Mei 2019, iklan Bukalapak Nego Cincai sudah ditonton sebanyak 15 juta kali di chanel youtube Bukalapak (Triwijanarko, 2018). Dan degan hal itu maka iklan yang menggunakan daya tarik humor dan musik cenderung lebih diminati oleh oarang-oang indonesia. Karena dengan menggunakan daya tarik emosional khususnya daya tarik humor dan musik orangorang cenderung lebih mudah mengingat brand kita daripada menggunakan gaya yang lainnya.

\section{SIMPULAN}

Simpulan dari iklan Bukalapak Nego Cincai ini adalah digunakannya daya tarik emisional dan daya tarik campuran. Dan dengan menggunakan tema yang bernuansa Tionghoa ini akan memberikan daya tarik emosional khususnya pada etnis Tionghoa dan iklan ini dirilis bertepatan dengan Hari Raya Imlek sehingga membuat iklan ini memiliki daya tarik emosional yang lebih pada etnis Tionghoa yang ada di Indonesia. 


\section{DAFTAR PUSTAKA}

Fahrini, R., \& Franzia, E. (2017). Citra Visual Dan Verbal. Dimensi DKV Seni Rupa Dan Desain, 2(2), 151-166. Retrieved from http://www.trijurnal.lemlit.trisakti.ac.id/index.php/seni/ article/view/2187

Morissan. (2007). periklanan komunikasi pemasaran terpadu. Periklanan Komunikasi Pemasaran Terpadu.

Triwijanarko, R. (2018). Kampanye Nego Cincai Bukalapak. Retrieved May 22, 2019, from https://marketeers.com/kampanye-nego-cincai-bukalapak/

Widagdo, P. B., \& Mada, U. G. (2016). Perkembangan Electronic Commerce (E-Commerce) di Indonesia Perkembangan Electronic Commerce (E-Commerce) di Indonesia. (December). 